\title{
Use of the cost-benefit analysis method in the risk management process of SMEs
}

\author{
Katarina Makka ${ }^{1, *}$, and Katarina Kampova ${ }^{1}$ \\ ${ }^{1}$ University of Zilina, Faculty of Security Engineering, Univerzitna 1, 01026 Zilina, Slovakia.
}

\begin{abstract}
Research background: Property protection is a worldwide very often used term in the conditions of various sectors. It represents a set of measures that have a preventive effect on the risk of damage to the building. The issue of property protection does not only concern organizations, but also every person who is the owner of a property in which his important interests are located. The protection of buildings is a current topic on a global scale, mainly to ensure the proper functioning through the protection of all important tangible and intangible assets of company.

Purpose of the article: The main idea of this article is to approach the issue and create a risk management process, focusing on dealing with risks in the conditions of a particular company, in this step we will use a cost-benefit analysis to help decide on the implementation or rejection of a project to protect the selected object.

Methods: Before applying the method of cost-benefit analysis to a specific case of protection of the object of the selected company, it was necessary to characterize the selected company and find out which risks are unacceptable through the creation of a risk management process. The risk management process was created based on structured and unstructured interviews with the company's employees.

Findings \& Value added: The proposed procedure for risk management and application of the method of cost-benefit analysis in the process of risk management are applicable in the conditions of any other organization in order to create an effective project for the protection of the object. If necessary, the procedure for using the cost-benefit analysis method can be adjusted to suit the needs and conditions of the problem of a particular organization.
\end{abstract}

Keywords: CBA analysis; company; property protection; security property, protection system.

JEL Classification: D61; G32; O22

\footnotetext{
*Corresponding author: katarina.makka@uniza.sk
} 


\section{Introduction}

Micro, small and medium-sized enterprises (SMEs) account for $99 \%$ of all enterprises in the EU. They provide two-thirds of jobs in the private sector and contribute more than half of the total added value created by the business in the EU. (Information sheets on the European Union, 2021), (Hudakova et al., 2017). The protection of these entities is therefore a constant topic (Gavurova at al., 2020), (Rowland et al., 2020). One of the important areas that is currently coming to the fore is the area of property protection and security of related assets (Hudakova et al., 2017). The importance of property protection and the security of related assets is increasing on a global scale, on the one hand with increasing value of protected assets and interests and on the other hand with ever-increasing opportunities to overcome elements of protection by intruders. The dynamics of change and increasing the impact on sustainable security, therefore, require a comprehensive systematic management mechanism based on standardized procedures and scientific methodsv (Valaskova et al., 2021). Such a mechanism, which allows not only intuitive, but above all exactly to approach the issue of security related to property, is a system of property protection. One of the possibilities of an effective approach to this system is the use of the Cost benefit analysis method. This method within the system of property protection aims to approach effectively in the selection of appropriate options for protection of buildings and allows SMEs to effectively manage not only the risks associated with property protection, but also to effectively manage their costs (Dvorsky et al., 2021).

\section{Methods}

Cost-benefit analysis is the process of comparing planned or estimated costs and benefits in order to decide whether a project is efficient or ineffective. In the process, it gradually answers the basic question: "What does it bring to and what does the implementation of an investment project take?" Costs indicate the amount of resources needed to implement a given project. Benefits indicate the value of the profit that can be expected in the implementation of a given project. Both costs and benefits are expressed in monetary units (Kampova et al., 2020), (Kampova and Makka, 2018). The basic terms used in the costbenefit analysis include:

- effects of the investment indicate all the impacts that the project has,

- costs are all negative effects,

- benefits are all positive effects,

- beneficiary refers to the entity affected by the effects of the investment,

- cash flow is a cash flow that takes the form of income or expenses,

- net cash flow indicates the difference between income and expenses,

- criteria indicators are indicators that fulfill the function of deciding whether or not a project is acceptable.

There are two types of cost-benefit analysis. The first is the ex-ante analysis, which is used in the period before the implementation of the project, when it is needed when deciding on a given project or when deciding on other possible options. The second is the ex-post analysis, which is used in the period after the end of the project for evaluation, while the aim is to specify the impact of the project in comparison with the expected results before its implementation (Masar et al., 2018), (Hudakova and Dvorsky, 2018).

The cost-benefit analysis consists of three main parts: the technical part, the financial analysis and the economic analysis (Kampova and Makka, 2018). The technical part is focused on defining the purpose of the project and its technical characteristics. Financial analysis deals with financial costs and benefits and its main goal is to evaluate the project in terms of financial efficiency for the investor. The economic analysis is related to the financial 
analysis and its aim is to evaluate the benefits of the project for all entities involved in it (Kampova and Makka, 2018).

The cost-benefit analysis can also be used in the field of protection of buildings, specifically in the process of risk management, after the complete development of the risk assessment process. A graphical representation of the use of this method in the field of property protection can be seen in the following figure (Kampova et al., 2020).

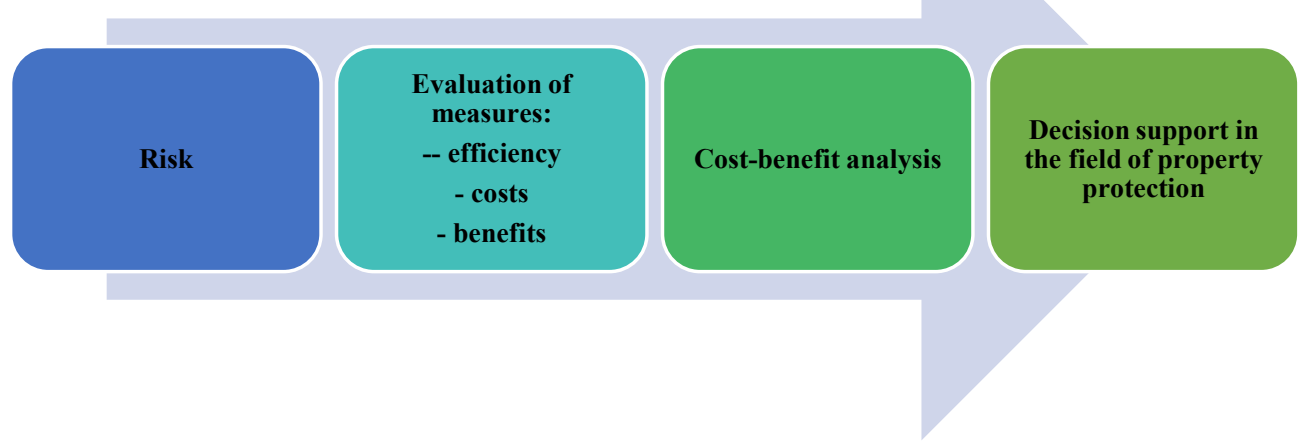

Figure 1. The process of cost-benefit analysis within the property protection.

Source: Kampova et al., 2020

In the first step, a selected risk enters the process, which needs to be minimized (Boros et al., 2019a). In the second step, it is necessary to evaluate the effectiveness of selected measures to reduce the risk (efficiency, calculation of costs, calculation of revenues). The effectiveness of the measures is expressed in terms of the extent to which the risk is eliminated or reduced through the implementation of the proposed measures (Buganova et al., 2021), (Boros et al., 2019a).

The cost of the measures depends on a comparison of the costs and the expected benefits, and it is necessary to assess the effectiveness of the funds spent on the implementation of these measures. The costs of implementing the measures should be quantified as accurately as possible. In the last step, it is necessary to create a cost-benefit analysis for the selected risk. The results of the cost-benefit analysis show how effective the solution would be and whether this project will be implemented or not.

\subsection{Application of the cost-benefit analysis method to a specific case of property protection}

The subject of interest is a company that specializes in the production, sale and service of independent sources of electricity based on internal combustion engines. The company is headquartered near the town of Martin and is one of the medium-sized companies with up to 50 employees. Based on the request of the owner to maintain the anonymity of the company, the work will not publish data such as the name of the company and a more detailed identification of the investigated location of the facility.

The company is one of the leading companies in the field of alternative sources of electricity in Central Europe. At present, it covers more than $40 \%$ of the Slovak market and exports its products to neighbouring countries, but also to other countries in Europe, Asia and Africa. The main goal of the company is the production of high quality products that are able to work even in the most demanding operating and climatic conditions. The company owns 
various certificates (eg ISO 9001 and ISO 14001), thanks to which it has become the subject of economic mobilization, which cooperates with the crisis management of the Ministry of Economy of the Slovak Republic.

\subsubsection{Design of a project for the property protection of a company}

The subject of the investment within this project is the creation of the protection of a property of a company. The protection of the property will be implemented mainly through the design of measures to ensure the security of this object. The aim of this project is to reduce security risks to an acceptable level, where the security of the object from the negative effects of real or latent threats is ensured (Lovecek et al., 2017). The beneficiary will be the company in question within this project. The project will be created with an emphasis on efficiency, ie. in order to reduce the risk as much as possible, while the financial costs of implementation will not exceed its benefits.

The first step is to create a zero variant that represents the current state. The last incident of burglary after preparation last occurred in 2016, resulting in the theft of $€ 20,000$ worth of company property and damage to the building. The cost of repairing the building was $€ 4,500$. The total financial loss due to this incident was estimated at $€ 24,500$, which represents a very high financial consequence for the company. In addition to the financial impacts already described, the incident also resulted in indirect financial consequences in the form of production restrictions due to the theft of important components and tools for the production of products and fines arising from the contract between the company and customers due to non-compliance with the agreed delivery date. The cause of theft by burglary by the perpetrator after the preparation occurred in 2016 was most likely due to insufficient security of the building. As a result, the company set up a camera system. Apart from the camera system, no other measures have been taken against the occurrence of another incident of this kind.

Table 1. Financial consequences in the event of a burglary event by the perpetrator after preparation

\begin{tabular}{|l|l|c|}
\hline Impact & Impact type & The amount $€$ \\
\hline \multirow{2}{*}{$\begin{array}{l}\text { Direct } \\
\text { impacts }\end{array}$} & $\begin{array}{l}\text { Theft of company assets (eg tools, devices, components, } \\
\text { products, cash) }\end{array}$ & 20000 \\
\cline { 2 - 3 } & $\begin{array}{l}\text { Damage to company property (eg broken windows, damage to } \\
\text { fencing, damage to doors and locks) }\end{array}$ & 4500 \\
\hline \multirow{2}{*}{$\begin{array}{l}\text { indirect } \\
\text { impacts }\end{array}$} & Restriction or complete cessation of production of products & 15000 \\
\cline { 2 - 3 } & $\begin{array}{l}\text { Fines arising from the contract between the company and } \\
\text { customers }\end{array}$ & 10000 \\
\hline \multicolumn{2}{|l|}{ Total amount } & 53500 \\
\hline
\end{tabular}

Source: authors (2020).

Based on the performed analysis in the company's premises to protect property of the organization from burglary, it is necessary to secure the object through (Kampová, et al., 2020), (Siser et al., 2017):

- mechanical barriers,

- technical security measures,

- creation of appropriate regime measures

A list of specific security features, including the price for their acquisition and installation, is given in Table 2 . 
Table 2. Selected security features for property protection

\begin{tabular}{|l|l|l|c|}
\hline Security feature & Producer & Type & $\begin{array}{l}\text { Total price including } \\
\text { installation } €\end{array}$ \\
\hline $\begin{array}{l}\text { Security grilles for } \\
\text { windows (18 pcs) }\end{array}$ & ADLO & Fixed window grille & 4230 \\
\hline $\begin{array}{l}\text { Security grilles for doors } \\
(4 \text { pcs })\end{array}$ & ADLO & $\begin{array}{l}\text { Openable grille with } \\
\text { locking for padlocks }\end{array}$ & 1280 \\
\hline $\begin{array}{l}\text { Alarm Detector Infrared } \\
\text { Beam Sensor (16 pcs) }\end{array}$ & SATEL & Activa-6-BR 6 & 4318 \\
\hline $\begin{array}{l}\text { Microwave barrier (4 } \\
\text { pcs) }\end{array}$ & AVS Electronics & BM60M, wireless & 4338 \\
\hline
\end{tabular}

Source: authors (2021)

The financial costs for the implementation of the project amount to $€ 16,691$. After installing the security elements, it is necessary to perform regular inspections. These inspections are necessary due to possible complications related to the functionality of individual security elements. The system will be inspected by authorized persons during four years, but at least once every six months. The estimated cost of this activity will be $€ 4,000$. Another part of the proposal for the protection of the property is a comparison of financial impacts. The financial impact is estimated before and after the implementation of security measures. Security measures are proposed for a burglary theft scenario with a ready intruder. The following table (tab. 3) provides an estimate of the financial impact of this scenario after implementation of security measures.

Table 3. Estimation of financial impact after implementation of security measures

\begin{tabular}{|l|l|c|}
\hline Impact & Type of impact & Sum $€$ \\
\hline \multirow{2}{*}{$\begin{array}{l}\text { Direct } \\
\text { impact }\end{array}$} & Theft of company assets (eg tools, devices, components, products, cash) & 5000 \\
\cline { 2 - 3 } & $\begin{array}{l}\text { Damage to company property (eg broken windows, damage to fencing, } \\
\text { damage to doors and locks) }\end{array}$ & 2500 \\
\hline $\begin{array}{l}\text { Indirect } \\
\text { effects }\end{array}$ & Restriction or complete interruption of product production & 5000 \\
\cline { 2 - 3 } & Fines arising from the contract between the company and customers & 0 \\
\hline \multicolumn{2}{|l}{ Total amount $€$} & 12500 \\
\hline
\end{tabular}

Source: author (2021)

\section{Results and discussion}

Based on the quantification of the costs and benefits of the proposed property protection project, it is possible to calculate the net present value (NPV) of the project for each year.

$$
N P V=\sum_{t=0}^{n} \frac{C F_{t}}{(1+r)^{t}},
$$

where:

NPV - Net Present Value,

$\mathrm{CF}_{\mathrm{t}}$ - Cash Flow in period of time $\mathrm{t}$,

$\mathrm{r}$ - discount rate (Stobierski, 2019).

For the project to be effective, the resul of net present value (NPV) must be positive or equal to zero. In this case, the positive values will represent the financial benefits gained through the project. If the final value is zero, this will mean that the project will not bring any financial benefits. 
Table 4. Quantification of costs and benefits in the investment and operational phase of the project

\begin{tabular}{|c|c|c|}
\hline The amount $\mathrm{v} €$ & Investment phase & Operational phase \\
\hline Costs & 16691 & 4000 \\
\hline Benefits & 0 & 41000 \\
\hline
\end{tabular}

Source: authors (2021)

Costs and benefits per year in the investment phase (zero year) and in the operational phase (4 years) are shown by a graph in the following figures (Figure 2)

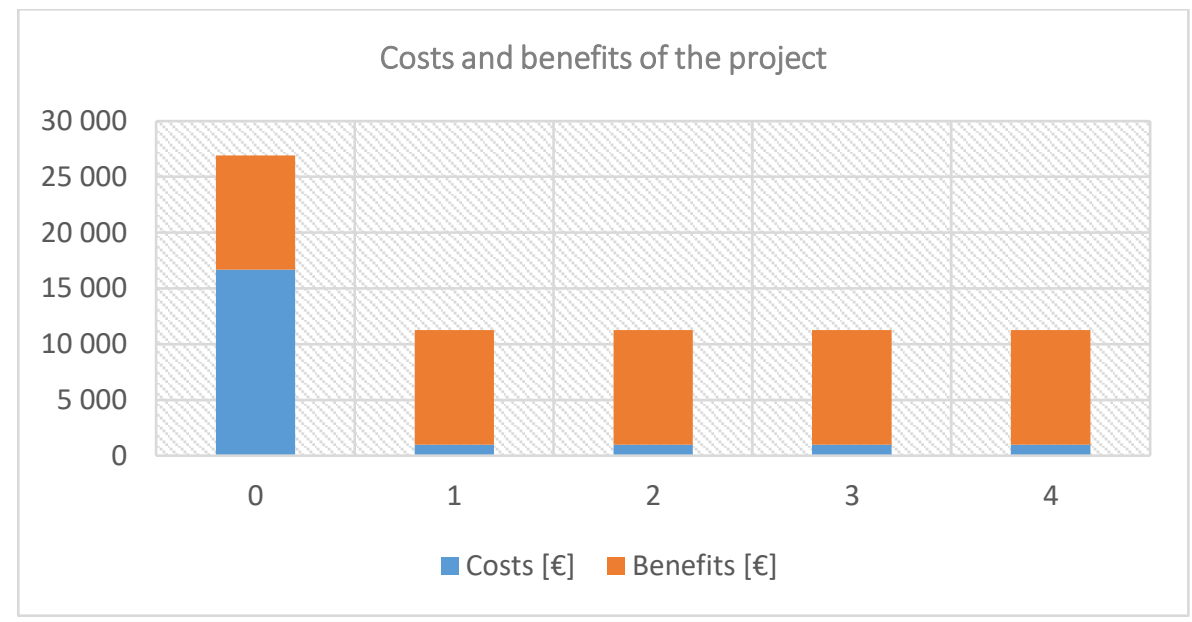

Figure 2. Cost - benefit comparison

Source: author (2021)

On the basis of quantified benefits and costs in the investment phase and operational phase, it is possible to calculate the net costs and benefits in each year. Values are obtained as a cost-benefit difference. The final result of the calculation of the net present value is compared with the eligibility criteria - net present value NPV $\geq 0$. The net present value (NPV) for this project was calculated $€ 16,885.53$, which is higher than 0 . The findings can be considered that the created project is acceptable and its implementation should be carried out.

\section{Conclusion}

The aim of the presented article was to identify the possibilities of using the method of costbenefit analysis in the process of risk management, in relation to the issue of protection of buildings in the conditions of a particular company. Before applying the cost-benefit analysis method, it was necessary to characterize the selected company and find out which risks are unacceptable by creating a risk management process for this company. The risk management process was created on the basis of structured and unstructured interviews with the company's employees. Through the characteristics of the object and the created risk management process, was found that the object does not have sufficient protection and the highest priority is the risk of theft by burglary by the perpetrator after preparation. The value of this risk was the highest mainly due to the fact that an incident of this kind in the company occurred in 2016. 
Due to the risk of theft by burglary after preparation, a project was created through the method of cost-benefit analysis to reduce this risk. The essence of the project was the proposal of measures to create protection of the building against this kind of risk. The measures were selected on the basis of their suitability for society. At each stage of the project, the steps that had to be taken together with the financial costs incurred were identified. The final evaluation of the project was a financial analysis which showed that the net present value (NPV) of the created project is $€ 16,885.53$. The condition for the effectiveness of the project was that the resulting amount of net present value was higher or equal to zero. The condition of efficiency has been met, which means that its implementation should take place.

The developed procedure for risk management and the method of cost-benefit analysis in the process of risk management can be applied in the conditions of any other organization in order to create an effective project for the protection of the property. If necessary, the procedure for using the cost-benefit analysis method can be adjusted to suit the needs and conditions of a particular organization and the problem beeing solved.

\section{Acknowledgements}

Publication of this paper was supported by the Scientific Grant Agency of the Ministry of Education, Science, Research and Sport of the Slovak Republic - VEGA No. 1/0243/20 Integrated risk management system in the conditions of contemporary changes in enterprise environment in Slovakia.

\section{References}

1. Boros, M., Zvakova, Z., \& Halaj, M. (2019a). Required Competencies of Security Managers for Decision-Making. INTED Proceedings, 3918-3923.

2. Boros, M., Zvakova, Z., \& Halaj, M. (2019b). Required Competencies of Security Managers for Decision-Making. INTED Proceedings, 3918-3923.

3. Buganova, K., Luskova, M., Kubas, J., Brutovsky, M., \& Slepecky, J. (2021). Sustainability of Business through Project Risk Identification with Use of Expert Estimates. Sustainability, 13(11), 6311.

4. Dvorsky, J., Belas, J., Gavurova, B., \& Brabenec, T. (2021). Business risk management in the context of small and medium-sized enterprises. Economic Research-Ekonomska Istraživanja, 34(1), 1690-1708.

5. Gavurova, B., Belas, J., Bilan, Y., \& Horak, J. (2020). Study of legislative and administrative obstacles to SMEs business in the Czech Republic and Slovakia. Oeconomia Copernicana, 11(4), 689-719.

6. Rowland, Z., Krulicky, T., \& Oliinyk, O. (2020). Capital cost quantification model in business activity planning: the evidence of the middle Europe countries. Ekonomickomanazerske spektrum, 14(1), 30-42.

7. Hudakova, M. \& Dvorsky, J. (2018). Assessing the risks and their sources in dependence on the rate of implementing the risk management process in the SMEs. EquilibriumQuarterly Journal of Economics and Economic Policy, 13(3), 543-567.

8. Hudakova, M . Schonfeld, J., Dvorsky, J. \& Luskova, M. (2017). The Market Risk Analysis and Methodology of its More Effective Management in SMEs in the Slovak Republic. Montenegrin Journal of Economics, 13(2), 151-161. 
9. Information sheets on the European Union, Small and medium enterprises (2021, October). https://www.europarl.europa.eu/factsheets/sk/sheet/63/male-a-strednepodniky

10. Kampova, K., \& Makka, K. (2018). Economic Aspects of the Risk Impact on the Fuel Distribution Enterprises. Transport Means - Proceedings of the International Conference, 231-235.

11. Kampova, K., Makka, K., \& Zvarikova, K. (2020). Cost benefit analysis within organization security management. SHS Web of Science, 74, 01010.

12. Kampova, K., Lovecek, T., \& Rehak, D. (2020). Quantitative approach to physical protection systems assessment of critical infrastructure elements: Use case in the Slovak Republic. International Journal of Critical Infrastructure Protection, 30, 100376.

13. Lovecek, T., Siser, A., \& Maris, L. (2017). Use Case of Waterwork Physical Protection System Robustness Evaluation as a Part of Slovak Critical Infrastructure. International Carnahan Conference on Security Technology Proceedings.

14. Masar, M., Hudakova, M. \& Luskova, M. (2018). Project Risk Management in Global Environment. In T. Kliestik (Eds.), Globalization and its Socio-Economic Consequences, Slovakia (pp.707-714).

15. Siser, A., Lovecek, T., \& Maris., L. (2017). Simulation of possible assault vectors in an attack using a real-life waterworks object as a use case. Procedia Engineering, 192, 794799.

16. Stobierski, T. (2019, September 5). How to do a Cost-benefit Analysis \& why it is important. https://online.hbs.edu/blog/post/cost-benefit-analysis

17. Valaskova, K., Adamko, P., Frajtova Michalikova, K., \& Macek, J. (2021). Quo Vadis, earnings management? Analysis of manipulation determinants in Central European environment. Oeconomia Copernicana, 12(3), 631-669. 